\title{
Indicadores da participação feminina em Ciência e Tecnologia
}

\section{Indicators of women participation in Brazilian Science and Technology}

\author{
Maria Cristina Piumbato Innocentini HAYASHI' \\ Rodrigo de Castro CABRERO² \\ Maria da Piedade Resende da COSTA ${ }^{3}$ \\ Carlos Roberto Massao HAYASHI ${ }^{4}$
}

\section{RESUMO}

Este trabalho tem por objetivo analisar a questão do gênero no setor de ciência e tecnologia nacional e examinar a situação das docentes que pertencem à comunidade científica da Universidade Federal de São Carlos (UFSCar). O estudo baseou-se em teorias sobre as questões do gênero na ciência e da participação feminina. Para a coleta de dados, utilizou-se o Diretório de Grupos de Pesquisa no Brasil/CNPq. Para aprofundamento da realidade das mulheres na UFSCar, realizou-se um levantamento adicional nos sites da instituição e do Instituto Brasileiro de Informação em Ciência e Tecnologia (IBICT). Conforme revelam os dados do Diretório, em 1995, a participação feminina alcançou 39\% dos cientistas e, em 2004, passou para 47\%. Na UFSCar, as mulheres representam $39,3 \%$ dos docentes, ocupam $1 / 3$ dos postos de comando e entre os discentes superam $55 \%$ dos estudantes. Destaca-se que ainda falta um caminho a percorrer para igualarem-se aos pesquisadores nos postos acadêmicos e áreas do conhecimento mais prestigiadas. Utilizar o potencial feminino é estratégico para avançar cientificamente.

Palavras-chave: Ciência e Tecnologia; indicadores de C\&T; participação feminina; produção científica.

\section{A B S T R A C T}

Nowadays, in Brazil, the role of women in science is a reality, but it is still essential to develop studies on their roles in academia. This work evaluates the gender situation in science and technology, focusing on the Federal University of São Carlos (UFSCar), in the state of São Paulo, Brazil, as a case study. Data about the female insertion in research groups in Brazil were collected using the Directory of Research Groups in Brazil published by the CNPq (the National Counsel for Scientific and Technological Development). The UFSCar situation was closely examined using the institutional website and also the site of the Brazilian Institute of Information in Science and Technology (IBICT). It is supposed that, in Brazil, women working in science will soon represent the major group. It should be mentioned that, according to the above mentioned Directory data, women were 39\% of the scientists in 1995 and this percentage increased to $47 \%$ in 2004 . Taking into account the situation at UFSCar, it can be said that women

\footnotetext{
' Doutora em Educação. Docente, Departamento de Ciência da Informação e Programa de Pós-Graduação em Educação Especial, Universidade Federal de São Carlos. Rodovia Washington Luis, Km 235, 13.560-905, São Carlos, SP, Brasil. Correspondência para/Correspondence to: M.C.P.I. HAYASHI.E-mail: <dmch@power.ufscar.br>.

2 Doutor em Educação Especial, Conselho Nacional de Desenvolvimento Científico e Tecnológico. E-mail: <rodrigocabrero@yahoo.com.br>.

${ }^{3}$ Doutora em Psicologia. Docente, Departamento de Psicologia e Programa de Pós-Graduação em Educação Especial, Universidade Federal de São Carlos. E-mail: <piedade@power.ufscar.br>.

${ }_{4}$ Doutor em Educação. Docente, Departamento de Ciência da Informação, Universidade Federal de São Carlos. Docente, Departamento de Ciência da Informação, Universidade Federal de São Carlos. E-mail: <massao@power.ufscar.br>.

Recebido em 28/9/2006 e aceito para publicação em 8/2/2007.
}

TransInformação, Campinas, 19(2):169-187, maio/ago., 2007 
are $39.3 \%$ of the academic staff, occupy $1 / 3$ of the command positions, and constitute $55 \%$ of the students. However, there are still room for increments of women participation in highly reputed academic positions and research areas. The full release of female potential is strategic for further advancements in science. The Brazilian scene must be better evaluated by investigating the women participation in other universities and research centers.

Keywords: Science and Technology, S\&T indicators; women participation; scientific production.

\section{NTRODU ÇÃ O}

Ao analisar quem produziu conhecimento nos últimos 300 anos, nota-se que a ciência é masculina. Muitas mulheres foram, e continuam sendo, excluídas da produção da ciência. Ainda hoje, quando as mulheres dominam numericamente alguns campos disciplinares, a imagem de cientista é associada aos homens.

O tema tem atraído a atenção de pesquisadores e autoridades públicas. Sardenberg (Brasil, 2006a), manifesta que "a tendência de crescente participação da mulher na pesquisa e desenvolvimento tecnológico é um forte sinal da modernidade do país". Contudo, conforme relata Schienbinger (2001, p.37) "o processo de trazer mulheres para a ciência exigiu, e vai continuar a exigir, profundas mudanças estruturais na cultura, métodos e conteúdo da ciência".

A formulação do gênero como categoria analítica propiciou a produção de uma ampla bibliografia que se refletiu no campo de estudos das relações de gênero na ciência. A produção científica internacional sobre o tema recebeu um grande impulso nos últimos trinta anos, conforme assinala Flores Espínola (2006, p.213), ao destacar que os primeiros estudos buscavam analisar a história de sua participação nas instituições científicas, centrando-se na história do acesso das mulheres aos significados de sua produção científica e seu status atual na profissão científica. Posteriormente, os estudos passaram a questionar o modo pelo qual a própria ciência e a tecnologia definiam a natureza da mulher e criticaram a natureza masculina da ciência. Por fim, os estudos preocuparam-se em revelar as distorções existentes nas próprias normas e métodos da ciência, como resultado da ausência das mulheres na ciência.

Entre os trabalhos de referência na área podem ser mencionados os estudos de Keller $(1985,2006)$, Longino (1990), Haraway (1991), Harding (1996), Schienbinger (2001). No cenário ibero-americano destacam-se os estudos de Fernándes Riús (2000), González García e Pérez-Sedeño (2002), Estebánez
(2003), Pérez-Sedeño (2004), Estebánez e LáscarisComneno (2004) entre outros.

Em relação à literatura nacional sobre essa temática, Leta (2003) assinala que "ela ainda é incipiente e, em geral, de difícil acesso e muito dispersa". Aliás, Lopes (1998) iá havia sugerido uma sistematização da produção científica sobre o tema, uma vez que esta é, em sua opinião, "uma área de estudos que, no país, se caracteriza pela dispersão de suas poucas publicações" e sobre a qual "muita coisa ainda está por ser feita". Por sua vez, Cabral (2006) argumenta que os estudos feministas da ciência e da tecnologia no Brasil são "um campo em crescimento", que tem recebido importantes contribuições, como os alentados estudos de Lopes $(1998,2000)$, Velho e León (1998), Citeli (2000), Soares (2001), Tabak (2002), Velho e Prochazka (2003), Leta (2003), Leta e Lewinson (2003), Melo; Lastres; Marques (2004), Melo e Lastres (2004), Maciel (2005), Melo e Oliveira (2006) e Costa (2006), entre outros.

Ao analisar a inserção das mulheres na ciência regional, Estébanez (2003) afirma que "multiplicaramse os estudos que vinculam as mulheres aos processos da ciência e da tecnologia na sociedade", no entanto, comenta que há carência de dados e estatísticas, sobretudo na América Latina, gerando obstáculos para a construção de uma avaliação da participação do sexo feminino na ciência:

No caso da região latino-americana, uma série de problemáticas comuns aos países da região opera contra uma maior acessibilidade de estatísticas e, portanto, afeta a visibilidade da situação da mulher na ciência. Entre as instituições científicas e educativas dos diversos países, há pouca tradição na produção desagregada por sexo na informação sobre seus recursos, atividades e resultados. Isso é traduzido nas estatísticas nacionais que oferecem um limitado número de indicadores desagregados no campo da ciência e da tecnologia. É pouco freqüente o acesso a estatísticas de maior especificidade como, por exemplo, a formação de doutoras, a participação em 
disciplinas ou a produção científica. Por outro lado, em termos gerais, é difícil conseguir informação desse tipo em séries temporais longas.

Sobre a importância do enfoque de gênero e a construção de indicadores de participação feminina na ciência e tecnologia, Estébanez e Láscaris-Comneno (2004) argumentam:

A aplicação do enfoque de gênero como marco de interpretação e de intervenção no campo da ciência alcançou também um reconhecimento específico na construção de indicadores de ciência e tecnologia na América Latina, ao ser considerado como uma ferramenta apropriada para melhorar a qualidade de nosso conhecimento sobre a ciência e sobre as especificidades da participação de mulheres e homens em seu desenvolvimento. Deste modo pode transformar-se em um modo eficaz de intervenção sobre os problemas de iniqüidade de gênero que afetam a região no campo cientíico e tecnológico. (tradução dos autores)

Neste contexto, para se verificar a participação feminina no dia-a-dia da atividade científica, há necessidade da construção de indicadores por órgãos governamentais, assim como do incremento das investigações científicas sobre o tema. Melo; Lastres; Marques (2004, p.16) ressaltam que "encontram-se lacunas graves nas informações fornecidas pelos órgãos competentes com relação à participação feminina nas várias esferas de atividades ligadas a CT\&l".

No entanto, no âmbito nacional, algumas iniciativas vêm alterando esta situação. Neste aspecto, pode-se mencionar o Diretório dos Grupos de Pesquisa do Brasil, administrado pelo Conselho Nacional de Desenvolvimento Científico e Tecnológico - CNPq, que apresenta importantes informações sobre a inserção de mulheres na ciência brasileira.

Justifica-se, assim, a importância, tanto de estudar a questão do gênero no meio científico, como de construir os indicadores de gênero na ciência e na tecnologia. Dando continuidade às pesquisas realizadas por Hayashi (2003, 2005), Hayashi; Hayashi; Mastrogirolamo (2004), este artigo relata os resultados de pesquisa que teve como objetivo analisar a participação feminina no setor de pesquisa científica e tecnológica do Brasil e verificar a situação da comunidade científica feminina na Universidade Federal de São Carlos (UFSCar).

A metodologia constou de duas etapas: a primeira, com vistas a construir o referencial teórico da pesquisa, procedeu ao levantamento bibliográfico sobre os temas: ciência e tecnologia no Brasil; universidades e presença feminina na área de Ciência e Tecnologia. A segunda etapa da pesquisa compreendeu a coleta de dados sobre a participação feminina no campo da ciência. Para esta finalidade foram consultados órgãos de fomento à pesquisa científica, como o Conselho Nacional de Desenvolvimento Científico e Tecnológico (CNPq) e fez-se o levantamento de informações sobre a comunidade feminina atuante em ciência e tecnologia e nas unidades acadêmicas e administrativas da UFSCar.

\section{Mulher na Ciência e na Tecnologia}

A historiografia da ciência no Brasil é recente e é reflexo da história de um país que teve suas bases na sociedade patriarcal, escravocrata, onde a elite letrada era pequena e a voz feminina baixa. Pioneiras como Berta Lutz e Heloísa Torres, precisaram sustentar-se em uma espécie de capital simbólico: a figura de um homem, filhas que eram do cientista Adolfo Lutz e do político Alberto Torres.

No meio acadêmico internacional, encontramse outros casos. Podem ser citados como exemplo a matemática Emny Noether que ajudou Einstein com seus cálculos a desenvolver a Teoria da Relatividade. Por sua vez, a imunologista Françoise Barré-Sinoussi, também é co-autora da descoberta do vírus da AIDS ao lado de Luc Montaigner e Robert Gallo e, no entanto, seu nome é desconhecido até mesmo entre membros da comunidade científica internacional. Com Rosalind Franklin não foi diferente, pois, enquanto suas fotografias por difração de raios $X$ foram elementoschave para Watson \& Crick proporem a dupla hélice do DNA, a autobiografia de Watson (1988) ridicularizou sua história. A contribuição de Rosalind Franklin não teve nenhum reconhecimento até que Anne Sayre escrevesse sua biografia, na qual conta uma história muito diferente: a da difícil situação de uma cientista, por ser mulher e judia, em uma instituição como o King's College de Londres, tradicionalmente masculina e claramente anglicana.

Ao longo da história, com raras exceções, percebe-se que o saber foi geralmente vetado à mulher: na Grécia, a mulher somente era admitida em algumas escolas filosóficas, como a platônica e pitagórica; na Idade Média, unicamente nos conventos, ainda que 
nem em todos os países - permitiam-lhes uma educação limitada. Historicamente, o ocultamento sistemático das mulheres também pode ser notado até na questão dos direitos sobre patentes. No passado, ao não ter a mulher o direito de propriedade, era o pai ou o marido ou algum outro homem que aparecia nos registros de patentes, como o responsável pelas invenções feitas pelas mulheres. Nos séculos XVII e XVIII, durante a Revolução Científica, entendia-se que somente os homens podiam atuar como pesquisadores. Neste período, não se questiona a manifesta inferioridade da mulher, mas se advoga por certa educação para que o mal seja menor. É o período do aparecimento das mulheres educadas e inclusive aparece uma figura típica da revolução científica: a scientific lady ou a femme savante, afrontada na literatura satírica, mas de fundamental importância para difusão da nova ciência, como assinala Schienbinger (2001).

As sociedades científicas Royal Society of London e Académie Royale des Sciences, ambas fundadas no século XVII, apenas admitiram mulheres no século XX: Em 1945, Marjory Stepheson e Kathlen Londsdale entram para a Royal Society e, em 1979, Yvone Choquet-Bruat, para a Académie. Na Espanha, a Real Academia de Farmácia, cuja fundação remonta a 1737, somente em 1987 admitiu uma mulher, a pesquisadora Maria Cascales. (González Garcia; Perez Sedeño, 2002)

No momento em que a ciência moderna se institucionaliza e se legitima, a mulher é dela excluída, repetindo uma dupla norma: a mulher é admitida na atividade científica praticamente como igual até que esta atividade se institucionalize ou se profissionalize; e o papel de uma mulher em determinada atividade científica é inversamente proporcional ao prestígio dessa atividade. Conforme o prestígio da atividade aumenta, diminui o papel da mulher.

A partir do século XIX, norte-americanas e européias foram admitidas nas universidades. Conforme Schienbinger (2001, p. 21) "passaram a ser admitidas nas universidades americanas e européias há apenas cerca de um século, e nos programas de pós-graduação, ainda mais tarde, e avisadas até e tão recentemente, como 1950, que mulheres não precisavam se candidatar para lecionar bioquímica".

Todavia, era reduzida a quantidade de mulheres que estava nas escolas e faculdades, pois elas eram preparadas para a vida no lar. Porém, algumas conse- guiam conquistar espaço na academia. Para Schienbinger (2001, p.61), "o exemplo mais excepcional foi o da física Laura Bassi que em 1732 tornou-se a segunda mulher na Europa a receber um grau universitário (depois da veneziana Elena Cornaro Piscopia em 1678) e a primeira a ser agraciada com uma cadeira na universidade".

Lembre-se que inicialmente as mulheres trabalhavam em pesquisa de modo informal. Aquelas que atuavam na atividade científica geralmente tinham vínculos familiares com cientistas renomados. A ausência dessa ligação representava na prática a falta de oportunidades para integrar-se à comunidade científica.

A queda de barreiras para a presença das mulheres nas Universidades, nos séculos XIX e XX tem a seguinte configuração. Na América do Norte, o quadro emerge em meados do século XIX; na Suíça, durante a década de 1860; na França, em 1880; na Alemanha, em 1900; e em Cambridge as restrições caem somente a partir de 1947. De fato, a contribuição da mulher à ciência e tecnologia não é um fato novo, uma vez que acontece já faz alguns séculos. Melo; Lastres; Marques (2004, p.4) mencionam que "não faz nem cem anos que os portões das universidades foram abertos às mulheres pela persistência das nossas avós e bisavós na luta por cidadania e educação".

Anteriormente, o acesso e permanência das mulheres nos laboratórios apresentavam-se com mais impedimentos. Existia o pensamento, sobretudo dos homens, de que as mulheres não possuíam competência ou aptidão para gerar conhecimento novo.

"A 'segunda onda do feminismo', ocorrida entre as décadas de 1960 e 1970, coincide, por sua vez, com um momento chave na história da luta das mulheres por acesso ao conhecimento" (Estébanez, 2003). Todavia, a segunda onda do feminismo caracteriza-se, não apenas por uma luta pelo acesso à educação e ao ensino superior, mas por questionar o fato de haver tão poucas mulheres estudando ciências e tecnologia ou trabalhando nessas áreas, terreno tradicionalmente masculino, e em postos de responsabilidade.

Uma análise do mercado de trabalho, de forma geral, permite dizer que "as mulheres nos países latinoamericanos precisam, em média, dois anos mais de escolaridade do que os homens para ter as mesmas oportunidades de emprego formal e quatro anos mais 
de escolaridade que eles para receber o mesmo salário" (Velho; Prochazka, 2003).

Discute-se a seguir algumas das dificuldades que a mulher encontra para seguir uma carreira científica:

- Dificuldade de conciliar a vida familiar com o trabalho, pois a dupla jornada (profissão e tarefas domésticas) continua a ser um fato, uma vez que o trabalho doméstico ainda é responsabilidade exclusiva da mulher. Segundo Melo; Lastres; Marques (2004, p.9), no Brasil não houve alteração do "modelo patriarcal vigente na sociedade. Ainda cabem às mulheres, fortemente, as responsabilidades domésticas e socializadoras das crianças, além dos cuidados com os velhos. Assim, as mulheres têm sempre a necessidade de articular os papéis familiares e profissionais para seu desempenho no mercado de trabalho".

- A gravidez é vista muitas vezes como um problema para as pesquisadoras; Ademais, há falta de creches e jardins de infância públicos, ou mesmo privados, a preços acessíveis;

- Há persistência na sociedade de fortes elementos de machismo e de estereótipos sexuais e preconceitos contra a mulher, que se alinham com a falta de condições e de estímulo.

- A mulher, por sua condição familiar, encontra ainda dificuldades em viajar para participar de congressos, tão essenciais para seu desenvolvimento na carreira.

Estes são apenas alguns dos fatores que afastam as mulheres das carreiras cientificas. Para Estébanez (2003), "os condicionamentos culturais provenientes da socialização prematura ou a situação particular da mulher em relação à maternidade têm sido destacados como fatores relevantes na hora de explicar as dificuldades das mulheres no desenvolvimento de carreiras científicas".

Se examinarmos a lista de todas as 141 pessoas que já receberam o Prêmio Nobel de Física, desde 1901 quando foi criado, até 1991, só encontraremos dois nomes de mulheres: Marie Curie - que, assim mesmo, dividiu o prêmio com o marido Pierre Curie e com outro francês, Antoine-Henri Becquerel, em 1903, e Maria Goeppert-Mayer - que também o dividiu com dois outros homens, em 1963.

O Prêmio Nobel de Química, nestes 91 anos, também só foi conferido a três mulheres: a mesma Marie
Curie, em 1911, desta vez sozinha; a Irene Joliot-Curie, filha de Marie e Pierre, em 1935; e a Dorothy M.C. Hodgkin, em 1964.

Conforme se sobe na escada do poder e prestígio, menos rostos femininos são vistos. É o "teto de cristal" no qual as mulheres esbarram e que deixa as mulheres à margem dos postos de maior poder, prestígio e responsabilidade em ciência e tecnologia. Em recente encontro nacional que discutiu as questões de gênero na ciência, verificou-se que "no Brasil, as mulheres são maioria nas universidades, ocupam espaços semelhantes aos homens na produção científica, porém, essa participação não se reflete no topo das carreiras acadêmicas. Raramente elas ocupam postos de destaque. Prova disso é que entre os 142 membros do Conselho de Reitores das Universidades Brasileiras (Crub), existem 122 reitores (86\%) e apenas 20 reitoras (14\%). As mulheres também são minorias como coordenadoras de grupos de pesquisa e membros de Conselhos Deliberativos do CNPq" (Nead, 2006). Zancan (Brasil, 2006b) argumenta que "mulheres vão para a Ciência, homens para as finanças. A Ciência não é atrativa para quem quer ganhar dinheiro".

Nesta linha de argumentação Estébanez (2003) acentua que:

o estancamento salarial do setor público em muitos países da região latino-americana, somado aos fenômenos de precarização das condições trabalhistas e desprestígio da carreira profissional, expulsa a mão-de-obra masculina do setor científico, particularmente o público. A existência de uma maior variedade de formas de incorporação de trabalho no setor de C\&T - tipicamente a modalidade de tempo parcial ou a maior flexibilidade horária - atrai as mulheres, mais pressionadas a compatibilizar seu rol reprodutivo com o produtivo.

A vida das mulheres nas academias também é definida pela territorialidade, pois estas tendem mais a ensinar e pesquisar em Humanidades do que em Ciências Naturais e Engenharias. As mulheres têm presença em universidades de prestígio, mas raramente são convidadas a integrar universidades de elite. Em Harvard, somente em 1989 a química Cynthia Friend foi admitida e, em 1992, a física Melissa Franklin.

Desta forma, devem ser realizados esforços para reconsiderar o papel da mulher na C\&T, recuperando do esquecimento as mulheres que, embora tenham feito destacáveis contribuições, foram silenciadas pela 
história tradicional. E deve-se superar quaisquer concepções estreitas da História da C\&T, por intermédio da reconstrução de disciplinas a partir de personagens femininas que efetivamente contribuíram para seu estabelecimento.

Atualmente, não se pode falar de exclusão explícita das mulheres nas universidades e centros de pesquisa e nem sequer falar sobre o peso ideológico da convicção de que a mulher seja intelectualmente inferior ao homem. Não se trata de rever a presença da mulher na C\&T, mas principalmente, de revelar vieses sexistas e androcêntricos nos pressupostos da ciência. Para Zancan (Brasil, 2006b) "a visão da mulher é distinta da masculina" e salienta que "é bom ter pesquisadores dos dois sexos, pois isso permite compartilhar uma visão com mais abrangência". Estébanez (2003) fala sobre o "potencial inovador da pesquisa científica gerada por mulheres".

Durante as últimas duas décadas a participação das mulheres no mercado de trabalho vem crescendo cada vez mais, tendo alcançado em várias áreas uma importância significativa. Não poderia ser diferente no sistema brasileiro de C\&T. A partir da mobilização política e da luta pela cidadania, as mulheres ocuparam as parcelas a que tinham direito na vida pública, e nada mais natural que o meio científico refletisse essas conquistas. A absorção de mulheres pelo sistema de C\&T brasileiro é um reflexo do que ocorre na sociedade, com concentrações e desigualdades localizadas.

\section{Participação da mulher no Diretório de Grupos de Pesquisa no Brasil/CNPq}

Diretório dos Grupos de Pesquisa no Brasil, coordenado pelo CNPq, apresenta informações sobre os grupos de pesquisa do país. Os levantamentos iniciaram-se em 1992. Atualmente, já foram realizados sete censos (1993, 1995, 1997, 2000, 2002, 2004 e $2006^{5}$ ). Com rapidez, é possível identificar quais os grupos e respectivos pesquisadores que estudam determinado tema e onde se encontram, além de obter dados para efetuar o contato, uma vez que as informações podem ser acessadas via Internet, no sitepágina do CNPq. Assim, torna-se possível, aos pesquisadores e setor produtivo, repassar e receber informações com agilidade. Além disso, o Diretório, em função do conjunto de dados existentes, permite ao gestor acadêmico e ao pesquisador planejar ações no campo científico. Acrescente-se que o Diretório registra uma grande parcela da evolução da ciência brasileira.

Ao longo dos anos, o Diretório tem exercido um importante papel para o conhecimento da situação da pesquisa nas universidades e centros de pesquisa brasileiros. Isto se consubstancia pela crescente participação das instituições, que em 2004 alcançam 335 entidades, 19.470 grupos e mais de 77 mil pesquisadores.

A Tabela 1 apresenta um quadro geral da evolução dos grupos de pesquisa no país. O levantamento sistemático da estrutura científica viabiliza idealizar ações, inclusive institucionalmente, para promover áreas estratégicas e/ou em expansão. Percebese que os pesquisadores doutores têm ampliado a participação quantitativa e percentual sobre o total de cientistas, o que demonstra uma melhoria na qualidade das pesquisas e condições para fortalecer os cursos de mestrado e doutorado. As expansões dos grupos e linhas de pesquisa mostram uma preocupação em aumentar a formalização e organização da investigação científica e tecnológica.

Tabela 1. Número de instituições, grupos, pesquisadores doutores (1993-2004).

\begin{tabular}{lcccccc}
\hline Censos & 1993 & 1995 & 1997 & 2000 & 2002 & 2004 \\
\hline Instituições & 99 & 158 & 181 & 224 & 268 & 335 \\
Grupos & 4.402 & 7.271 & 8.632 & 11.760 & 15.158 & 19.470 \\
Pesquisadores (P) & 21.541 & 26.779 & 33.980 & 48.781 & 56.891 & 77.649 \\
Pesquisadores doutores (D) & 10.994 & 14.308 & 18.536 & 27.662 & 34.349 & 47.973 \\
\hline (D)/(P) em \% & 51 & 53 & 55 & 57 & 60 & 62 \\
\hline
\end{tabular}

Fonte: CNPq.

${ }^{5}$ Os resultados do Censo 2006 ainda não foram divulgados.

TransInformação, Campinas, 19(2):169-187, maio/ago., 2007 
A distribuição das pesquisadoras nos Censos do Diretório de Grupos de Pesquisa no Brasil, de acordo com a liderança, pode ser observada na Tabela 2.

Pode-se observar na Tabela 2 que, no censo de 1995, em relação ao total de cientistas cadastrados na base, havia uma vantagem numérica dos homens (61\%) atuantes em pesquisa, em comparação com as mulheres (39\%). Contudo, com o passar dos anos, nota-se que as mulheres estão reduzindo a diferença. Os dados censitários de 2004 revelam que o sexo feminino representa $47 \%$ dos pesquisadores atuantes em pesquisa. De um lado, os pesquisadores vivenciaram uma redução de $13 \%$ e as pesquisadoras passaram por uma ampliação de $20 \%$, sobre o total de cientistas atuantes em pesquisa.

Focalizando o aspecto da liderança, a Tabela 2 revela que no Censo de 1995, na condição de "Líder de pesquisa", os homens representavam $66 \%$ e as mulheres $34 \%$, enquanto que, como não-líderes, os homens alcançavam $59 \%$ e as mulheres, $41 \%$. Em 2004, houve uma expansão da participação feminina, que saltou para $42 \%$ entre os líderes e $49 \%$ para os não-líderes. Entre os doutores, independente da condição de liderança, $57,7 \%$ são homens e $42,3 \%$ mulheres. Portanto, há indicativo de um descompasso entre a participação das mulheres e a ocupação de espaços de maior prestígio. Todavia, Cabrero et al. (2006, p.247) mostram que, na área científica brasileira, "a participação feminina amplia-se quantitativamente e qualitativamente".

Olinto $(2004$, p. 11$)$ desenvolveu um estudo por faixa etária, individualizando os dados sobre homens (homens líderes sobre o total de homens) e mulheres (mulheres líderes sobre o total de mulheres) e afirma que,

focalizando o efeito da faixa etária, se observa que a participação de mulheres na liderança é menor que a masculina entre investigadores mais jovens, mas aumenta relativamente entre as faixas de mais idade. Estes resultados são compatíveis também com evidências que sugerem que o status acadêmico da mulher em relação ao do homem tende a se nivelar ao longo do tempo. (tradução dos autores)

É interessante verificar a participação do sexo feminino na ciência global. Ao analisar dados de diversos países e continentes e de estudos comparados sobre a presença das mulheres na ciência em campos específicos do conhecimento, Olinto (2004) verificou que a média proporcional não ultrapassa $30 \%$. Por sua vez, para Velho e Prochazka (2003)

[....] graças ao crescimento da participação das mulheres na educação superior e na pós-graduação, hoje elas representam entre 35 e $50 \%$ do total de pesquisadores dos países latinoamericanos. Tais proporções encontram-se bem acima daquela exibida pelas mulheres nos países da União Européia onde, em média, mais de $2 / 3$ dos pesquisadores em institutos públicos de pesquisa e 3/4 daqueles nas instituições de ensino superior são homens; ou nos Estados Unidos, onde em cada 5 pesquisadores se encontra apenas 1 mulher.

Análise da situação latino-americana, com a inclusão de Estados Unidos, Portugal e Espanha demonstrou que as mulheres representam $20 \%$ dos pesquisadores. Ademais, somente na Argentina, Paraguai e Uruguai nota-se uma equiparação entre os sexos no ambiente da ciência. Em países mais avançados, como Estados Unidos e Espanha, surgem as menores taxas de inserção do sexo feminino no meio acadêmico. Com exceção dos Estados Unidos, os demais países examinados vivenciaram ao longo dos anos de 1990 uma expansão percentual das pesquisadoras. De modo geral, caminha-se para uma melhor distribuição

Tabela 2. Distribuição percentual dos pesquisadores por sexo, segundo a condição de liderança - 1995-2004 (total pela condição de liderança: 100\%)*.

\begin{tabular}{|c|c|c|c|c|c|c|c|c|c|c|}
\hline \multirow{2}{*}{ Condição de liderança } & \multicolumn{2}{|c|}{1995} & \multicolumn{2}{|c|}{1997} & \multicolumn{2}{|c|}{2000} & \multicolumn{2}{|c|}{2002} & \multicolumn{2}{|c|}{2004} \\
\hline & $\mathrm{H}$ & M & $\mathrm{H}$ & $M$ & $\mathrm{H}$ & M & $\mathrm{H}$ & M & $\mathrm{H}$ & M \\
\hline Líderes & 66 & 34 & 63 & 37 & 61 & 39 & 59 & 41 & 58 & 42 \\
\hline Não líderes & 59 & 41 & 56 & 44 & 54 & 46 & 51 & 49 & 51 & 49 \\
\hline Total & 61 & 39 & 58 & 42 & 56 & 44 & 54 & 46 & 53 & 47 \\
\hline
\end{tabular}

Fonte: CNPq. $\left({ }^{*}\right)$ Para o Censo de 1993, os dados não estão disponíveis. 
proporcional na ciência, com perspectivas de que as mulheres, em vários países estudados, superem os homens (Estébanez, 2003).

Quando se analisa a distribuição dos pesquisadores por sexo e faixa etária no censo 2004 do Diretório de Grupos de Pesquisa no Brasil, constatase, conforme demonstra a Tabela 3, que nas faixas etárias de 20 a 24 anos e de 25 a 29 anos prevalecem as mulheres, e estas praticamente empatam com os homens na faixa de 30 a 34 anos. A seguir, percebe-se que nas faixas a partir de 35 anos ocorre o domínio masculino.

Além disso, conforme se eleva a idade de análise, amplia-se a participação dos homens, que na faixa a partir de 65 anos atingem 66,8\% dos cientistas. Evidencia-se uma tendência de equilíbrio dentro de alguns anos, com possibilidade de predominância das mulheres, pois nas faixas de menor idade o sexo feminino é maioria.

Por sua vez, os dados censitários sobre os estudantes, relacionados com as coletas de 2000, 2002 e 2004 revelam que as mulheres estão na dianteira. No âmbito do Programa Institucional de Bolsas de Iniciação Científica (PIBIC/CNPq) percebe-se que o sexo feminino é maioria. Galiza (2005, p. 1) acentua que:

os números de modalidades que representam o início da vida acadêmica e científica - PIBIC/IC e Mestrado - mostram um predomínio feminino, o que significa a expectativa de mudanças no futuro, já que, a partir do doutorado, o número de homens supera o de mulheres.

A Tabela 4 apresenta a distribuição de pesquisadores por área de conhecimento no censo 2004 do Diretório de Grupos de Pesquisa no Brasil/CNPq. Pode-se observar que, quando a análise recai sobre as áreas do conhecimento, os homens dominam os seguintes ramos: Engenharias; Ciências Exatas e da Terra; Ciências Agrárias; e Ciências Sociais Aplicadas, com apenas $53,8 \%$. Por outro lado, as mulheres dominam nas áreas de Lingüística, Letras e Artes; Ciências Humanas; Ciências da Saúde; e Ciências Biológicas, com alguma vantagem.

Melo; Lastres; Marques (2004, p. 1) afirmam que:

há um crescente número de mulheres profissionais engajadas em atividades científicas e que este contingente de pesquisadores avança na direção da maior qualificação profissional embora, por razões históricas, permaneça menor a presença feminina em áreas tradicionalmente ocupadas por homens, especialmente nos setores das engenharias e na pesquisa tecnológica aplicada.

Os dados da Tabela 4 confirmam a posição das pesquisadoras. No que se refere às Engenharias, o sexo feminino representa pouco mais de 1/4 dos pesquisadores. Estébanez (2003) acrescenta que

Tabela 3. Distribuição de pesquisadores por sexo e faixa etária 2004.

\begin{tabular}{lcccccc}
\hline Faixa etária & Total & Homens & Mulheres & $\mathrm{NI}$ & $\% \mathrm{H}^{* *}$ & $\% \mathrm{M}^{* *}$ \\
\hline Até 19 & 22 & 14 & 5 & 3 & 73,7 & 26,3 \\
20 a 24 & 881 & 374 & 494 & 13 & 43,1 & 56,9 \\
25 a 29 & 4.803 & 2.297 & 2.454 & 52 & 48,3 & 51,7 \\
30 a 34 & 9.582 & 4.819 & 4.704 & 59 & 50,6 & 49,4 \\
35 a 39 & 13.405 & 7.114 & 6.221 & 70 & 53,3 & 46,7 \\
40 a 44 & 14.357 & 7.458 & 6.811 & 88 & 52,3 & 47,7 \\
45 a 49 & 12.679 & 6.498 & 6.136 & 45 & 51,4 & 48,6 \\
50 a 54 & 10.602 & 5.820 & 4.749 & 33 & 55,1 & 44,9 \\
55 a 59 & 6.360 & 3.656 & 2.680 & 24 & 57,7 & 42,3 \\
60 a 64 & 3.000 & 1.816 & 1.180 & 4 & 60,6 & 39,4 \\
65 ou + & 1.926 & 1.283 & 638 & 5 & 66,8 & 33,2 \\
Não informou & 32 & 23 & 8 & 1 & 74,2 & 25,8 \\
\hline Total & 77.649 & 41.172 & 36.080 & 397 & 53,3 & 46,7 \\
\hline
\end{tabular}

Fonte: CNPq. Notas: ${ }^{*} \mathrm{NI}=$ Não informou. ${ }^{* * \%}$ calculada sobre o total informado. 
Tabela 4. Número de pesquisadores por sexo segundo grande área predominante do grupo, no Censo 2004/CNPq*

\begin{tabular}{lcccccc}
\hline Brasil/Grande área & \multicolumn{2}{c}{ Total geral $(\%)$} & \multicolumn{2}{c}{ Masculino $(\%)$} & \multicolumn{2}{c}{ Feminino $(\%)$} \\
\hline Ciências Agrárias & 9.798 & 11,3 & 6.412 & 65,5 & 3.386 & 34,5 \\
Ciências Biológicas & 10.578 & 12,1 & 5.002 & 47,3 & 5.576 & 52,7 \\
Ciências da Saúde & 15.300 & 17,5 & 6.311 & 41,2 & 8.989 & 58,8 \\
Ciências Exatas e da Terra & 10.152 & 11,6 & 6.932 & 68,3 & 3.220 & 31,7 \\
Ciências Humanas & 14.936 & 17,1 & 5.938 & 39,8 & 8.998 & 60,2 \\
Ciências Sociais Aplicadas & 9.370 & 10,7 & 5.038 & 53,8 & 4.332 & 46,2 \\
Engenharias & 12.970 & 14,9 & 9.671 & 74,6 & 3.299 & 25,4 \\
Lingǘstica, Letras e Artes & 4.214 & 4,8 & 1.393 & 33,1 & 2.821 & 66,9 \\
\hline Totais & 87.318 & 100 & 46.697 & 53,1 & 40.621 & 46,5 \\
\hline
\end{tabular}

Fonte: CNPq. $\left({ }^{*}\right)$ Não há dupla contagem no número de pesquisadores na dimensão mais desagregada da tabela e não foram consideradas os pesquisadores que não informaram o sexo.

Em países com diferente situação de base como, por exemplo, Brasil, Argentina, Venezuela, Uruguai, constata-se que as mulheres são igualmente maioria no campo das ciências sociais e humanidades em geral, têm uma participação igualitária ou levemente maior na química, biotecnologia e ciências da saúde, e uma presença muito baixa nas ciências exatas, em particular na física, matemática e computação e nas engenharias.

No caso brasileiro, quando se analisa o conjunto de Ciências Humanas e Sociais, assim como as Ciências da Saúde (Tabela 4), constata-se que o sexo feminino é maioria. Verificações nas Ciências Exatas e da Terra e Engenharias possibilitam dizer que são áreas predominantemente ocupadas por homens, o que vem ratificar o entendimento da investigadora.

Olinto (2004) comenta que procuram-se as razões para a maior participação do sexo masculino no campo científico. Pesquisas sobre a trajetória das crianças mostram que meninas e meninos alcançam os mesmos desempenhos em matemática e na área de exatas. Entretanto, questões culturais influenciam na escolha das áreas. Assim, meninas dirigem-se majoritariamente para áreas que não exigem de forma determinante habilidades com números.

Em 2003, o CNPq concedeu 50.245,8 bolsas no país e foi registrado o sexo do bolsista. Neste caso, as mulheres ficaram com $24.285,7$ bolsas $(48,3 \%)$ e os homens com 25.960,1 (51,7\%). No entanto, com relação ao topo da carreira de pesquisador, mulheres coordenam 33 (18,6\%) entre os 177 Programas de Apoio a Núcleos de Excelência (PRONEX), relacionados aos Editais de 2003 e 2004. Mas comenta-se que em uma das fases do "Projeto Genoma Brasileiro, cerca de metade dos laboratórios participantes eram coordenados por mulheres" (Brasil, 2006c).

\section{A participação feminina na C\&T da UFSCar}

A Universidade Federal de São Carlos - UFSCar é uma instituição de ensino superior, localizada no interior do estado de São Paulo. A UFSCar foi criada em 1968; entretanto, o funcionamento de cursos de graduação começou no ano de 1970.

O corpo docente atual da UFSCar é constituído por 627 docentes, dos quais $247(39,3 \%)$ são do sexo feminino e $380(60,6 \%)$ do sexo masculino ${ }^{6}$. Ao observar-se a titulação dos professores da UFSCar destaca-se que $89,96 \%$ possuem doutorado e $9,86 \%$ têm mestrado. Além disso, 97,9\% estão em regime de dedicação exclusiva.

Neste caso, ao se comparar com os dados da média nacional, expostos na Tabela 2, as pesquisadoras da UFSCar apresentam níveis percentuais bastante próximos aos auferidos no Censo de 1995 e, nessa

\footnotetext{
${ }^{6}$ As informações relacionadas com a atuação feminina no âmbito da UFSCar foram retiradas dos sites da instituição, do Instituto Brasileiro de Informação em Ciência e Tecnologia - IBICT e do Diretório dos Grupos de Pesquisa do CNPq.
} 
lógica, inferiores à média nacional registrada no Censo de 2004. A ausência de concursos regulares possivelmente foi um dos fatores que restringiu o aumento da participação feminina entre os docentes da UFSCar. Além disso, a carreira docente nas federais geralmente é longa. Assim, as substituições do quadro levam algum tempo. Pode-se acrescentar que, dentro do ambiente docente, tratam-se de vagas valorizadas, o que amplia a disputa entre homens e mulheres.

A Tabela 5 mostra a distribuição do corpo docente da UFSCar entre os quatro Centros e seus respectivos Departamentos na estrutura administrativa da instituição, a saber: Centro de Ciências Exatas e de Tecnologia (CCET), Centro de Educação e Ciências Humanas (CECH), Centro de Ciências Biológicas e da Saúde (CCBS) e Centro de Ciências Agrárias (CCA).

A coleta foi realizada em outubro de 2006, no site da Secretaria de Recursos Humanos da UFSCar (SRH) e foram considerados os professores que estavam listados (efetivos e substitutos). Foram excluídos os dados referentes ao campus de Sorocaba, cujo corpo docente é composto por 22 homens e 23 mulheres, tendo em vista a não existência de Departamentos na estrutura administrativa deste campus.

Os dados apresentados na Tabela 5 permitem verificar que as mulheres são maioria no Centro de Ciências Biológicas e da Saúde (60,2\%), com domínio expressivo nas sub-áreas de Terapia Ocupacional (100\%), Enfermagem (95,2\%) e Medicina (62,5\%). Verifica-se aqui que há correspondência entre estes achados e as abordagens teóricas sobre a feminização do trabalho na área de saúde. Sobre este aspecto, a literatura aponta a área de saúde como um lugar que, historicamente, concentra o trabalho feminino, sendo que, no contexto do setor hospitalar, as mulheres aparecem em porcentagem superior, em torno de 70\% do conjunto dos trabalhadores, conforme relatam Pastore e Dalla Rosa (2006).

No campo da Enfermagem, Lopes e Leal (2005, p. 110$)$ retomam os aspectos sócio-históricos desta área e mencionam "a noção de cuidado (de saúde à família), enquanto ação concebida como feminina e produto das "qualidades naturais" das mulheres, que fornece atributos e coerência ao seu exercício no espaço formal das relações de trabalho na saúde". Nogueira-Martins (2002) também chama a atenção para o fato de que algumas profissões de saúde, entre elas a Enfermagem, são constituídas por população predominantemente feminina. Entretanto, reporta-se à pesquisa realizada por Machado (1997) para lembrar que este verificou ser de apenas $32,8 \%$ a presença das mulheres na Medicina. Estes dados foram corroborados no trabalho de Lopes e Leal (2005), que demonstraram ser o exercício da Medicina no Brasil uma profissão predominantemente masculina, pois $67,3 \%$ dos profissionais são homens e $32,7 \%$ são mulheres.

Na área de Ciências Humanas e Sociais Aplicadas, representadas na UFSCar pelo Centro de Educação e Ciências Humanas, verificou-se que, do total de 84 pesquisadoras $(58,3 \%$ em relação aos homens), o destaque localiza-se nas sub-áreas de Psicologia (89,3\%), Metodologia do Ensino (81\%), e Ciência da Informação (77\%). Estes achados parecem confirmar a opinião de Yannoulas; Vallejos; Lenarduzzi (2000, p.436) que mencionam observar-se "a tendência de agrupamento das alunas universitárias em disciplinas vinculadas aos serviços como são as profissões nas áreas de Comunicação, Educação, Humanidades e Saúde".

Na UFSCar, na área de Ciências Agrárias, as mulheres atingem $31,6 \%$ e na área de Exatas e Tecnologia a participação feminina é de 22, $1 \%$. Nestas duas áreas, as mulheres não conseguem a dianteira em nenhuma sub-área. Estes resultados parecem confirmar os argumentos de Yannoulas; Vallejos; Lenarduzzi (2000, p.436):

[...] antigos guetos masculinos (como Veterinária) estariam se transformando em disciplinas neutras do ponto de vista da composição dos alunos em relação ao sexo. Outros cursos estariam passando pelo processo de feminização (Medicina). Engenharia e Agronomia se mantêm masculinizadas. Sem dúvida, as carreiras e especialidades que se feminizaram mais cedo (como Educação) conservam este caráter. Este fenômeno indicaria que nem todas as carreiras transformam-se em direção a um equilíbrio quanto à composição sexual.

Na sub-área de Letras o fato se repete na UFSCar, com 58,9\% de participação feminina. Entretanto, na sub-área de Artes há maior presença masculina $(66,6 \%)$, possivelmente pela inserção da subárea de Comunicação Social e do perfil do curso de graduação em Imagem e Som com habilitação em Produção Audiovisual que possui um forte acento nas tecnologias de informação e comunicação. Sobre estes achados é interessante notar que pesquisa realizada por Melo; Lastres; Marques (2004, p. 19) apontou que: 
Tabela 5. Distribuição do corpo docente da UFSCar por sexo, departamento e centro.

\begin{tabular}{|c|c|c|c|c|c|}
\hline \multirow{2}{*}{ Centros/Departamentos } & \multicolumn{2}{|c|}{ Mulheres } & \multicolumn{2}{|c|}{ Homens } & \multirow{2}{*}{ Total } \\
\hline & $\mathrm{N}$ & $\%$ & $\mathrm{~N}$ & $\%$ & \\
\hline \multicolumn{6}{|l|}{ Centro de Ciências e de Tecnologia (CCET) } \\
\hline Estatística & 6 & 35,3 & 11 & 64,7 & 17 \\
\hline Química & 15 & 34,9 & 28 & 65,1 & 43 \\
\hline Matemática & 6 & 15,8 & 32 & 84,2 & 38 \\
\hline Física & 5 & 16,1 & 26 & 83,9 & 31 \\
\hline Computação & 10 & 30,3 & 23 & 69,7 & 33 \\
\hline Engenharia de Materiais & 5 & 12,2 & 36 & 87,8 & 41 \\
\hline Engenharia Química & 6 & 20,7 & 23 & 79,3 & 29 \\
\hline Engenharia de Produção & 5 & 14,3 & 30 & 85,7 & 35 \\
\hline Engenharia Civil & 5 & 15,6 & 27 & 84,4 & 32 \\
\hline Sub-Total & 63 & 21,0 & 236 & 79,0 & 299 \\
\hline \multicolumn{6}{|l|}{ Centro de Educação e Ciências Humanas ( $\mathrm{CECH})$} \\
\hline Ciências Sociais & 7 & 31,8 & 15 & 68,2 & 22 \\
\hline Educação & 6 & 42,9 & 8 & 57,1 & 14 \\
\hline Filosofia e Metodologia das Ciências & 3 & 27,3 & 8 & 72,7 & 11 \\
\hline Metodologia do Ensino & 17 & 81,0 & 4 & 19,0 & 21 \\
\hline Psicologia & 25 & 89,3 & 3 & 10,7 & 28 \\
\hline Letras & 10 & 58,9 & 7 & 41,2 & 17 \\
\hline Artes e Comunicação & 6 & 33,3 & 12 & 66,6 & 18 \\
\hline Ciência da Informação & 10 & 77,0 & 3 & 23,0 & 13 \\
\hline Sub-Total & 84 & 58,3 & 60 & 41,7 & 144 \\
\hline \multicolumn{6}{|l|}{ Centro de Ciências Biológicas e da Saúde (CCBS) } \\
\hline Ciências Fisiológicas & 4 & 44,4 & 5 & 55,5 & 9 \\
\hline Hidrobiologia & 5 & 38,5 & 8 & 61,5 & 13 \\
\hline Botânica & 4 & 50,0 & 4 & 50,0 & 8 \\
\hline Ecologia e Biologia Evolutiva & 4 & 44,4 & 5 & 55,5 & 9 \\
\hline Morfologia e Patologia & 4 & 50,0 & 4 & 50,0 & 8 \\
\hline Educação Física e Motricidade Humana & 5 & 45,5 & 6 & 54,5 & 11 \\
\hline Enfermagem & 20 & 95,2 & 1 & 4,8 & 21 \\
\hline Fisioterapia & 11 & 57,9 & 8 & 42,1 & 19 \\
\hline Terapia Ocupacional & 13 & 100,0 & 0 & 0 & 13 \\
\hline Genética e Evolução & 3 & 27,3 & 8 & 72,7 & 11 \\
\hline Medicina & 15 & 62,5 & 9 & 37,5 & 24 \\
\hline Sub-Total & 88 & 60,2 & 58 & 39,8 & 146 \\
\hline \multicolumn{6}{|l|}{ Centro de Ciências Agrárias (CCA) } \\
\hline Recursos Naturais e Proteção Ambiental & 2 & 25,0 & 6 & 75,0 & 8 \\
\hline Biotecnologia Vegetal & 6 & 40,0 & 9 & 60,0 & 15 \\
\hline Tecnologia Agroindustrial e Sócio-Economia Rural & 4 & 26,7 & 11 & 73,3 & 15 \\
\hline Sub-Total & 12 & 31,6 & 26 & 68,4 & 38 \\
\hline Total & 247 & 39,3 & 380 & 60,6 & 627 \\
\hline
\end{tabular}

Fonte: Atualização dos dados de Hayashi, Hayashi e Mastrogirolamo (2004) com base em dados coletados na Secretaria de Recursos Humanos da UFSCar (2006). 
[...] Lingüística, Letras e Artes são áreas do conhecimento afeitas à vocação feminina socialmente construída, desde o século XIX, quando a tarefa de ensinar as crianças a falar, ler e escrever foi atribuído às mulheres. No entanto, são áreas de conhecimento com pouco prestígio social e a presença feminina indica fortemente isso.

Comparando os dados da UFSCar, com o Censo de 2004 do Diretório de Grupos de Pesquisa no Brasil/CNPq verifica-se que as áreas de Biológicas e da Saúde, quando analisadas em conjunto, no levantamento censitário, apresentam participação das mulheres de $56,3 \%$, inferiores aos $60,2 \%$ que emergem na UFSCar.

Observa-se que a situação do $\mathrm{CECH}$, quando cotejada com o Censo 2004/CNPq, apresenta resultados bastante próximos. Nas Ciências Agrárias, as mulheres representam, pelos dados nacionais, $34,5 \%$, uma porcentagem discretamente superior à registrada na UFSCar $(31,6 \%)$. Neste caso, a presença masculina é mais forte; e quando se somam as áreas de Ciências Exatas e da Terra, à de Engenharias, verificase que, pelas informações do Diretório (Tabela 4), o sexo feminino representa $28,2 \%$ e, pelos dados obtidos da UFSCar, 21\%. Desta forma, não há, na confrontação das informações, grandes disparidades entre as informações do quadro brasileiro com a realidade encontrada na universidade.

Ressalta-se que em cargos hierárquicos de relevância no contexto acadêmico, há uma incipiente participação das mulheres. Conforme relata Fernandes (Brasil, 2006a) "as mulheres ainda não ocupam posições de maior prestígio acadêmico". A autora ainda questiona: "quantas são reitoras nas grandes universidades? Quantas estão na Academia Brasileira de Ciências? Quantas já dirigiram o CNPq?" (Brasil, 2006a). No âmbito da América Latina, Estébanez (2003) afirma que,

[...] quanto maior a hierarquia acadêmica ou científica, menor a participação feminina com independência do campo disciplinar. Em alguns países, como Argentina, com porcentagens de participação que superam $50 \%$ no âmbito científico universitário, as mulheres descendem até $25 \%$ nos postos mais altos na escala acadêmica.
Por outro lado, Zancan (Brasil, 2006b) acentua que: "no Brasil, as mulheres chegam a cargos do topo da carreira acadêmica. Nas universidades americanas e européias, isso é muito mais difícil". Sabe-se que os gêneros não têm o mesmo espaço ou oportunidades. Ainda Abós (2006), ao comentar um então recente informe da Comissão Européia sobre o papel das mulheres na ciência, menciona que em países onde a discriminação é menor, as mulheres, entretanto, representam somente em torno de 13 a $18 \%$ dos professores titulares nas universidades e, em certos casos, há países em que esta taxa é de 0 e $1 \%$.

Bagdassarian (2006) comenta que quando se analisa a presença da mulher no âmbito científico se detectam duas classes de segregação: a horizontal e a vertical. Ou seja, a segregação horizontal tem a ver com a disciplina, ou seja, ao fato de que a maioria das cientistas se concentra nas ciências biológicas e médicas, enquanto que nas disciplinas consideradas "duras", como a Física e a Engenharia, a representação é baixa. Por outro lado, devido à segregação vertical, que se refere ao avanço na carreira acadêmica, as mulheres cientistas se caracterizam por ocupar postos não permanentes, temporários ou de curta duração e, como conseqüência, nestes casos a taxa de abandono do sistema é maior do que a dos homens e também maior do que em outras profissões.

Em relação a esse aspecto, vejamos como se configura a participação feminina na carreira acadêmica na UFSCar, tomando como referência os cargos administrativos ocupados pelas cientistas.

A análise da participação das mulheres em cargos de chefia na UFSCar envolveu 25 posições $^{7}$, e atingiu a reitoria, vice-reitoria, 4 pró-reitorias, prefeitura universitária, 10 diretorias, procuradoria geral, chefia de gabinete, 4 secretarias gerais e a coordenação especial para o meio ambiente. Os homens ocupam 16 cadeiras e as mulheres 9, o que representa, respectivamente, $64 \%$ e $36 \%$ das posições. Constata-se, portanto, a força masculina na direção da UFSCar e fica patente a falta de equilíbrio entre o espaço ocupado por homens e mulheres.

No intuito de investigar se esta situação refletese em outros cargos de confiança na estrutura administrativa, tais como Chefe de Departamento, Coor-

${ }^{7}$ Conforme lista disponível em UFSCar (2006).

TransInformação, Campinas, 19(2):169-187, maio/ago., 2007 
denação de Curso de Graduação e Coordenação de Curso de Pós-Graduação verificou-se que a participação feminina também é menor do que a dos homens, confirmando assim o referido na literatura da área; ou seja, quando se trata de ocupar cargos, os homens têm maior participação do que as mulheres. Estes dados podem ser verificados nas Tabelas 6 e 7, a seguir, que mostra a presença feminina em cargos de confiança na estrutura administrativa da UFSCar, mais a taxa de crescimento desta participação, nos anos 2003 e 2006.

Os dados indicam que no ano de 2006, dos 33 cargos de confiança do CCET, $(21,2 \%)$ são ocupados por mulheres. $\mathrm{N}^{\circ} \mathrm{CECH}$, dos 21 postos, 13 (62\%) têm a condução feminina. No CCBS, entre os
25 postos de confiança, 15 (60\%) tem à frente mulheres. No CCA, dos 5 cargos, 4 (80\%) são ocupados por homens. No total de 84 postos de confiança, 36 $(42,8 \%)$ são de responsabilidade das mulheres.

Confrontando estes achados com os de Mastrogirolamo (2003), pode-se verificar na Tabela 7 que houve um crescimento de 10,4\%, na participação feminina nos cargos de confiança na UFSCar,

Estes achados também vêm ao encontro daqueles relatados por Bagdassarian (2006, p.53) que, ao analisar a segregação vertical das mulheres cientistas, verificou que na Universidad de Zaragoza $4,6 \%$ dos catedráticos são mulheres, sendo que a média na Espanha é de 13,4\%, enquanto a média de toda a

Tabela 6. Participação feminina em cargos de confiança na estrutura administrativa UFSCar nos anos 2003 e 2006.

\begin{tabular}{|c|c|c|c|c|c|c|}
\hline \multirow{3}{*}{ Centros } & \multicolumn{2}{|c|}{ Chefia de Departamentos } & \multicolumn{2}{|c|}{ Coordenação de Curso Graduação } & \multicolumn{2}{|c|}{$\begin{array}{c}\text { Coordenação de Cursos de } \\
\text { Pós-Graduação }\end{array}$} \\
\hline & \multicolumn{6}{|c|}{2006} \\
\hline & Homens & Mulheres & Homens & Mulheres & Homens & Mulheres \\
\hline CCET & 9 & 0 & 10 & 4 & 7 & 3 \\
\hline CCBS & 4 & 7 & 4 & 6 & 2 & 2 \\
\hline $\mathrm{CECH}$ & 4 & 4 & 2 & 5 & 2 & 4 \\
\hline CCA & 3 & 0 & 0 & 1 & 1 & 0 \\
\hline \multirow[t]{2}{*}{ Total } & \multicolumn{6}{|c|}{84} \\
\hline & \multicolumn{6}{|c|}{2003} \\
\hline CCET & 9 & 0 & 11 & 3 & 8 & 2 \\
\hline CCBS & 5 & 5 & 1 & 4 & 2 & 2 \\
\hline $\mathrm{CECH}$ & 6 & 2 & 3 & 4 & 2 & 2 \\
\hline $\mathrm{CCA}$ & 3 & 0 & 0 & 0 & 0 & 0 \\
\hline Total & \multicolumn{6}{|c|}{74} \\
\hline
\end{tabular}

Fontes: Mastrogirolamo (2003) e UFSCar/SRH (2006).

Tabela 7. Taxa de crescimento de participação feminina nos cargos de confiança da UFSCar.

\begin{tabular}{|c|c|c|c|c|c|c|c|}
\hline \multirow[b]{2}{*}{ Centros } & \multicolumn{2}{|c|}{2003} & \multirow{2}{*}{$\% M$} & \multicolumn{2}{|c|}{2006} & \multirow{2}{*}{$\% M$} & \multirow{2}{*}{$\begin{array}{c}\text { Crescimento } \\
\% \\
\end{array}$} \\
\hline & $\mathrm{H}$ & $M$ & & $\mathrm{H}$ & $M$ & & \\
\hline CCET & 28 & 5 & 15,1 & 26 & 7 & 21,2 & 6,1 \\
\hline CCBS & 8 & 11 & 57,9 & 10 & 15 & 60 & 2,1 \\
\hline $\mathrm{CECH}$ & 11 & 8 & 42,1 & 8 & 13 & 62 & 19,8 \\
\hline CCA & 3 & 0 & 0 & 4 & 1 & 20 & 20,0 \\
\hline Total & 50 & 24 & 32,4 & 48 & 36 & 42,8 & 10,4 \\
\hline
\end{tabular}

Fontes: Mastrogirolamo (2003) e UFSCar/SRH (2006). 
Europa é de 6\%. A autora assinala que, na School of Science do MIT (Massachussets Institute of Technology, nos EUA), somente $8 \%$ dos postos permanentes são ocupados por mulheres.

Ao compararmos os dados de Bagdassarian (2006) com aqueles encontrados na pesquisa realizada na UFSCar, verifica-se que as mulheres ocupam 21,7\% das posições de professores titulares (10 entre 46 homens) e 23,6\% das posições de associados (34 entre 110 homens). Ou seja, 23,2\% do total de 190 cargos, distribuídos entre as duas categorias mais elevadas das cinco existentes (titular, associado, adjunto, assistente e auxiliar). A partir de dados como estes, confirma-se a visão de que,

[...] basta olhar quem ocupa as pró-reitorias e diretorias nas universidades, a composição dos conselhos superiores das mais variadas agências de financiamento, os comitês assessores, a filiação honorífica às academias, e rapidamente se revela a preponderância masculina. $\bigcirc$ que é ainda bastante desconhecido nas nossas condições é se, e em que medida, essa exclusão das mulheres é provocada por práticas discriminatórias (ainda que involuntárias e inconscientes) e que efeitos tal exclusão tem na atual e futura participação da mulher no sistema de C\&T, assim como na natureza do conhecimento que se produz (Velho; Prochazka, 2003).

Na pesquisa relatada neste artigo também se verificou a participação das mulheres no desenvolvimento de investigações científicas. Desta forma, utilizaram-se dados do IBICT, no que se refere à concessão de bolsas de produtividade em pesquisa, as quais, após análise das propostas por consultores, são repassadas pelo $\mathrm{CNPq}$ aos pesquisadores produtivos e atuantes em C\&T. A seguir, foram levantados os dados junto ao Diretório dos Grupos de Pesquisa, coordenado pelo CNPq, para comparar a situação das pesquisadoras em relação aos pesquisadores da UFSCar.
A Tabela 8 demonstra que 143 cientistas da UFSCar foram contemplados com bolsa de produtividade em pesquisa do CNPq, em 2006. Neste grupo, são 36 mulheres enquadradas como bolsistas ou seja, aproximadamente $25,2 \%$; o que significa que de cada quatro bolsas, apenas uma foi concedida para cientista do sexo feminino.

Verifica-se na Tabela 8 que, dentre 36 mulheres, apenas duas bolsistas se posicionam no nível mais elevado (1A), ou seja 5,5\% deste total, e 3 na categoria IB $(8,3 \%)$.

$\mathrm{Na}$ Tabela 9, encontra-se a distribuição das bolsas de produtividade em pesquisa, por sub-área de conhecimento e por sexo na UFSCar.

Pode-se observar na Tabela 9 que a maioria das bolsas de produtividade em pesquisa da UFSCar se encontra na área de Exatas e Tecnológicas (61,5\%). No CCET, as mulheres possuem 12 bolsas, frente às 76 conquistadas pelos homens. A maior participação percentual das mulheres acontece no CCBS (56\%): este é o único Centro em que as mulheres superam os homens. No $\mathrm{CECH}$, as pesquisadoras têm 10 bolsas e os pesquisadores 16. Confirma-se, no âmbito da UFSCar, o fato de que no topo da carreira as mulheres não possuem grande representatividade.

Entretanto, os dados revelam a atuação das mulheres em vários campos do conhecimento, desenvolvendo uma pesquisa reconhecida. Velho e Prochazka (2003) afirmam que,

[...] uma vez dentro do sistema, em termos de progresso na carreira científica e posição hierárquica, as mulheres na América Latina têm que enfrentar as mesmas dificuldades e barreiras que suas colegas pesquisadoras nos demais países do mundo. Hierarquia implica poder de decisão, que é importante para a seleção de tópicos de pesquisa e alocação de recursos, e é exatamente neste aspecto que a posição das mulheres deteriora sensivelmente.

Tabela 8. Bolsistas de produtividade em pesquisa/CNPq na UFSCar, por sexo e nível de classificação, em 2006.

\begin{tabular}{|c|c|c|c|c|c|c|c|c|c|c|c|c|}
\hline \multirow{3}{*}{ Sexo } & \multicolumn{10}{|c|}{ Nível da Bolsa } & \multirow{2}{*}{\multicolumn{2}{|c|}{ Total }} \\
\hline & \multicolumn{2}{|c|}{$1 \mathrm{~A}$} & \multicolumn{2}{|c|}{ 1B } & \multicolumn{2}{|c|}{$1 \mathrm{C}$} & \multicolumn{2}{|c|}{$1 D$} & \multicolumn{2}{|c|}{2} & & \\
\hline & $\mathrm{N}$ & $\%$ & $\mathrm{~N}$ & $\%$ & $\mathrm{~N}$ & $\%$ & $\mathrm{~N}$ & $\%$ & $\mathrm{~N}$ & $\%$ & $\mathrm{~N}$ & $\%$ \\
\hline Homens & 9 & 81,8 & 16 & 84,4 & 23 & 69,7 & 30 & 81,1 & 29 & 67,4 & 107 & 74,8 \\
\hline Mulheres & 2 & 18,2 & 3 & 15,8 & 10 & 30,3 & 7 & 18,9 & 14 & 32,6 & 36 & 25,2 \\
\hline Total & 11 & 100,0 & 19 & 100,0 & 33 & 100,0 & 37 & 100,0 & 43 & 100,0 & 143 & 100,0 \\
\hline
\end{tabular}

Fontes: IBICT - CNPq. 
Tabela 9. Distribuição das bolsas de produtividade em pesquisa do CNPq na UFSCar, por sexo, sub-área e centros em 2006.

\begin{tabular}{|c|c|c|}
\hline Sub-áreas/Centros & Mulheres & Homens \\
\hline \multicolumn{3}{|l|}{ Engenharias e Ciências Exatas (CCET) } \\
\hline Computação & 1 & 1 \\
\hline Engenharia de Materiais & 4 & 25 \\
\hline Engenharia de Produção & 1 & 6 \\
\hline Engenharia de Transporte & 1 & 0 \\
\hline Engenharia Química & 1 & 6 \\
\hline Estatística & 0 & 2 \\
\hline Física & 0 & 16 \\
\hline Matemática & 0 & 6 \\
\hline Química & 4 & 14 \\
\hline Sub-Total & $12(13,6 \%)$ & $76(86,4 \%)$ \\
\hline \multicolumn{3}{|l|}{ Ciências Humanas e Sociais Aplicadas (CECH) } \\
\hline Ciência Política & 0 & 2 \\
\hline Ciências Sociais & 1 & 3 \\
\hline Educação & 5 & 3 \\
\hline Filosofia & 0 & 4 \\
\hline Planejamento Urbano e Regional & 1 & 0 \\
\hline Psicologia & 3 & 4 \\
\hline Sub-Total & $10(38,5 \%)$ & $16(61,5 \%)$ \\
\hline \multicolumn{3}{|l|}{ Ciências Biológicas (CCBS) } \\
\hline Bioquímica & 1 & 0 \\
\hline Botânica & 1 & 1 \\
\hline Ciências Fisiológicas & 1 & 1 \\
\hline Ecologia e Biologia Evolutiva & 1 & 2 \\
\hline Fisioterapia & 7 & 1 \\
\hline Genética e Evolução & 1 & 5 \\
\hline Zoologia & 2 & 1 \\
\hline Sub-Total & $14(56 \%)$ & $11(44 \%)$ \\
\hline \multicolumn{3}{|l|}{ Ciências Agrárias (CCA) } \\
\hline Recursos Pesqueiros e Engenharia de Pesca & 0 & 4 \\
\hline Sub-total & 0 & $4(100 \%)$ \\
\hline Total & $36(25,2 \%)$ & $107(74,8 \%)$ \\
\hline
\end{tabular}

Fonte: UFSCar. Pesquisa realizada em fevereiro de 2006.

Nota: As áreas de Bioquímica, Ciência Política, Engenharia de Transporte, Planejamento Urbano e Regional, Recursos Pesqueiros e Engenharia de Pesca e Zoologia foram agrupadas tendo em vista a lołação de origem do pesquisador na UFSCar.

As informações do censo 2004 do Diretório de Grupos de Pesquisa no Brasil/CNPq permitem afirmar que, nessa coleta, foram cadastrados 928 pesquisadores da UFSCar. Destes, 797 (85,88\%) são doutores, 90 $(9,70 \%)$ são mestres, $35(3,77 \%)$ são graduados ou especialistas; em $6(0,65 \%)$ casos não há registros sobre a titulação máxima. Entre os doutores, 335 (42,03\%)
183 
Desta forma, entre os 927 pesquisadores da UFSCar inseridos no Diretório (Tabela 10) e com informação do sexo, 400 (43,15\%) são mulheres e 527 $(56,85 \%)$ são homens. A comparação com a Tabela 5 - que mostra os dados do corpo docente da UFSCar demonstra que no âmbito dos pesquisadores inseridos no Diretório surge maior equilíbrio entre homens e mulheres. Neste caso, no que se refere à participação feminina, os dados se aproximam ao auferido no Censo de 2000 (Tabela 2).

A Tabela 11 demonstra que na grande área de Engenharias os pesquisadores respondem por mais de $26 \%$ dos docentes atuantes em pesquisa. Com a adição do percentual dos cientistas das Ciências Exatas e da Terra e das Ciências Humanas, chega-se a praticamente 2/3 da força de pesquisa da UFSCar incluída no Diretório. Ressalta-se que existem pesquisadores que participam de grupos de pesquisa em diferentes grandes áreas. Desta forma, foram computados em cada grande área, acarretando ampliação do total geral de pesquisadores.

Na Tabela 11, verifica-se que o sexo masculino predomina nas áreas de Ciências Agrárias e Ciências Biológicas, e tem forte vantagem nas Ciências Exatas e

Tabela 10. Distribuição dos pesquisadores da UFSCar no Censo 2004 do Diretório, por sexo.

\begin{tabular}{lcc}
\hline Pesquisadores & Masculino & Feminino \\
\hline $927^{*}$ & 527 & 400 \\
$100 \%$ & $56,85 \%$ & $43,15 \%$ \\
\hline
\end{tabular}

Fonte: CNPq. $\left({ }^{*}\right) 1$ pesquisador não informou o sexo. da Terra e nas Engenharias. O sexo feminino surge na dianteira nas áreas de Ciências da Saúde, Ciências Humanas, Ciências Sociais Aplicadas (nesta, com leve vantagem) e na de Lingüística, Letras e Artes.

Na UFSCar, existem 327 líderes de grupos de pesquisa cadastrados no Diretório. Entre esses, 134 $(40,98 \%)$ são mulheres e $193(59,02 \%)$ são homens. De outra maneira, foram abrangidos pelos dados censitários 1.916 estudantes, sendo 809 (42,22\%) do sexo masculino, $1057(55,17)$ do sexo feminino e 50 $(2,61 \%)$ sem informação sobre o sexo. Acrescenta-se que, em todos os níveis de treinamento (graduação, especialização, mestrado e doutorado) o sexo feminino é maioria.

No Programa Institucional de Bolsas de Iniciação Científica - PIBIC do CNPq, mulheres bolsistas da UFSCar, no biênio 2002/2003, têm larga vantagem nas seguintes áreas: Biológicas, Humanas, Saúde, Lingüística, Letras e Artes e conseguem a maioria nas Sociais Aplicadas. Os bolsistas ficaram com grande dianteira nas Ciências Agrárias e reduzida vantagem nas Engenharias. Aparece um empate dos sexos entre bolsistas nas Ciências Exatas e da Terra. Os dados vêm confirmar a propensão para crescimento do sexo feminino no contexto da pesquisa brasileira.

\section{CONSIDERAÇÕES FINAIS}

A produção científica, durante muitos anos, foi praticamente exclusividade dos homens. Na atualidade, percebe-se que as mulheres ocupam, devido aos esforços realizados, maior espaço no ambiente de

Tabela 11. Número de pesquisadores da UFSCar por sexo e por grande área predominante do grupo, Censo 2004*.

184

\begin{tabular}{lcccc}
\hline Grande área & Total geral & Masculino & Feminino & Não Informado \\
\hline Ciências Agrárias & 34 & 22 & 12 & 0 \\
Ciências Biológicas & 110 & 60 & 50 & 0 \\
Ciências da Saúde & 121 & 39 & 82 & 0 \\
Ciências Exatas e da Terra & 196 & 144 & 51 & 1 \\
Ciências Humanas & 196 & 83 & 113 & 0 \\
Ciências Sociais Aplicadas & 44 & 183 & 77 & 0 \\
Engenharias & 260 & 5 & 16 & 0 \\
Lingüística, Letras e Artes & 21 & 556 & 425 & 1 \\
\hline Totais & 982 & &
\end{tabular}

Fonte: CNPq.

TransInformação, Campinas, 19(2):169-187, maio/ago., 2007 
pesquisa científica e tecnológica. No Brasil, esta situação é realidade. Entretanto, sente-se a necessidade de indicadores produzidos pelo setor público, e desenvolvimento de maior número de estudos sobre a questão do gênero na área de C\&T, para melhor visualização da contribuição de cada sexo.

Ressalta-se que o Diretório dos Grupos de Pesquisa é importante instrumento para mostrar a situação do pesquisador brasileiro. Por meio do Diretório é possível verificar, por exemplo, os homens e mulheres envolvidos com a geração de conhecimento. Além disso, existe a expansão de investigações com diagnósticos sobre a contribuição individualizada dos sexos feminino e masculino.

As mulheres, embora estejam participando mais ativamente da ciência, ainda enfrentam dificuldades para ocupar postos acadêmicos de maior expressão. Conforme Zancan (Brasil, 2006b), nas instituições de ensino superior americanas e européias, os obstáculos para o sexo feminino atingir as posições mais elevadas na carreira universitária são mais presentes do que no Brasil; segundo Zancan é interessante possuir cientistas de ambos os sexos, pois homens e mulheres têm visões diferenciadas.

Na ciência brasileira, conforme dados do Diretório, em 1995 as mulheres representavam 39\% dos pesquisadores em atividade. Em 2004, já eram 47\%. Em vários países examinados ocorre uma ampliação da participação do sexo feminino no meio científico. Em geral, nos países avançados a presença das mulheres é inferior ao percentual registrado no Brasil. Uma das explicações está relacionada com a relevância que alcançou o setor científico. Este quadro estimula o envolvimento do sexo masculino com a carreira acadêmica. Estima-se que, no planeta, as mulheres representem no máximo 30\% dos pesquisadores (Olinto, 2004) e que, na América Latina, elas sejam 35\% a 50\% (Velho; Prochazka, 2003). No Brasil, o crescimento foi constante e acredita-se que em breve o número de mulheres pesquisadoras alcançará o dos homens.

Destaca-se que as mulheres predominam entre os pesquisadores em faixas etárias mais jovens e são minoria significativa a partir de 35 anos. Conforme a idade aumenta, os homens predominam. Quando a análise recai sobre os pesquisadores que não são líderes de grupos de pesquisa, já existe um grande equilíbrio, pois as mulheres atingiram $49 \%$ do total em 2004. Mas, quando se trata de pesquisadores líderes, o sexo feminino representa $42 \%$. Examinando os investigadores com título de doutor, observa-se que as mulheres alcançam 42,3\%. Assim, constata-se que apesar da expansão das mulheres na ciência brasileira, ainda é necessário consolidar sua participação, visando alcançar maior representação nos postos de maior expressão acadêmica.

O estudo dos dados do Diretório, por grande área do conhecimento, demonstra que as mulheres dominam nas áreas de Ciências Biológicas; Ciências da Saúde, Ciências Humanas, e Lingüística, Letras e Artes. É nítida a reduzida participação do sexo feminino na área das Engenharias, das Ciências Exatas e das Ciências Agrárias. Fatores históricos e culturais influenciam na escolha do campo de atuação. Em geral, áreas mais prestigiadas são dominadas por homens.

Na UFSCar, as mulheres são 39,3\% do corpo docente. $\bigcirc$ percentual equivale à média nacional registrada nos dados censitários de 1995. Portanto, inferiores à média brasileira exposta pelo censo 2004 do Diretório. A situação pode ter surgido em função da falta de concursos regulares e da permanência por muitos anos dos professores nas instituições federais de ensino, o que possivelmente afeta a renovação do quadro docente.

A distribuição dos pesquisadores por área do conhecimento na UFSCar é similar ao verificado no Diretório de Grupos de Pesquisa no Brasil/CNPq e na literatura. As mulheres predominam na área de Ciências Biológicas e da Saúde, assim como na área de Ciências Humanas e Sociais. Os homens são maioria nas áreas de Ciências Exatas e da Terra, nas Engenharias e nas Ciências Agrárias.

Em posições de poder, as professoras ficam com 1/3 das cadeiras, em comparação aos professores. Em outras situações de destaque acadêmico na UFSCar, como a bolsa de produtividade em pesquisa concedida pelo $C N P q$, percebe-se que as mulheres representam aproximadamente 1/4 dos bolsistas. As cientistas com doutorado, inseridas no Diretório dos Grupos de Pesquisa, representam cerca de $42 \%$. Entre os líderes de grupos de pesquisa, o sexo feminino detém aproximadamente $41 \%$ das posições. Por outro lado, as discentes preponderam no programa de iniciação científica, o PIBIC/CNPq. Entre os estudantes, as mulheres representam mais de 55\% do alunado inserido no Diretório e, independente do nível de treinamento, estão na dianteira. Esse "mapeamento" da UFSCar 
confirma a participação feminina no contexto da formação de pessoas, na geração de conhecimento e na atuação em diferentes áreas. Todavia, ali, o domínio masculino está mais acentuado em comparação ao estágio vivenciado no Brasil atual. Contudo, ao exame do corpo discente exposto no Diretório, fortalece-se a estimativa de que as mulheres ampliam sua ocupação da ciência.

Inegavelmente, o sexo feminino está presente na ciência brasileira, com maior força em certos campos do conhecimento. Por outro lado, a proporção das mulheres em postos de maior prestígio, não reflete o tamanho da contribuição. Mas, a tendência de maior inserção das mulheres é clara, inclusive em posições acadêmicas de destaque. Lembre-se que a ciência, por milênios, foi dominada pelos homens. Entretanto, saber utilizar o grande banco de talentos que se coloca à disposição do país, significa fortalecer o potencial competitivo da comunidade acadêmica nacional.

\section{A GRADECIMENTOS}

Aos pareceristas anônimos pelas recomendações e sugestões feitas à versão anterior deste trabalho e à Flavia Daniela Mastrogirolamo, bolsista PIBIC/CNPq/UFSCar, pela colaboração no desenvolvimento da etapa inicial da pesquisa.

\section{REFERÊNCIAS}

ABÓS, A. Ciencias de mujer. In: CONGRESO IBEROAMERICANO DE CIÊNCIA, TECNOLOGIA Y GÊNERO. 6., 2006, Zaragoza. Anais... Zaragoza: Prensas Universitárias, 2006.

BAGDASSARIAN, E.C. Paridad en el sistema CyT desde el punto de vista de las ióvenes investigadoras y tecnólogas afecta tener hijos y hijas? In: VI CONGRESO IBEROAMERICANO DE CIÊNCIA, TECNOLOGIA Y GÊNERO. 6., 2006, Zaragoza. Anais... Zaragoza: Prensas Universitárias, 2006. p.53-54.

BRASIL. Ministério da Ciência e Tecnologia (MCT). 2006a. A ciência brasileira descobre a competência feminina: espinhos. Disponível em: <http://ftp.mct.gov.br/especial/mulherl.htm>. Acesso em: 20 mar. 2006

BRASIL. Ministério da Ciência e Tecnologia (MCT). 2006b. A ciência brasileira descobre a competência feminina: Glaci Zancan. Disponível em: <http://ftp.mct.gov.br/especial/ mulher4.htm >. Acesso em: 20 mar. 2006.

BRASIL. Ministério da Ciência e Tecnologia (MCT). A ciência brasileira descobre a competência feminina: jovem cientista. 2006c. Disponível em: <http://ftp.mct.gov.br/especial/ mulher3.htm >. Acesso em: 20 mar. 2006.

CABRAL, C.G. O conhecimento dialogicamente situado: histórias de vida, valores humanistas e consciência crítica de professoras do Centro Tecnológico da UFSC. 2006. Tese (Doutorado em Educação Científica e Tecnológica) - Programa de Pós-Graduação em Educação Científica e Tecnológica, Universidade Federal de Santa Catarina, Florianópolis, 2006.

CABRERO, R.C. et al. Questão do gênero no setor científico nacional. In: CONGRESSO INTERNACIONAL DE LEITURA E FORMAÇÃO DE PROFESSORES, 2, 2006, Salvador. Leitura e Formação de Professores. João Pessoa: Editora Universitária/UFPB, 2006.

CITELI, M.T. Mulheres nas ciências: mapeando campos de estudo. In: LOPES, M.M. (Org.). Cadernos Pagu: gênero, ciência e história. Campinas: Unicamp, n. 15, p.39-75, 2000.

CNPQ. Diretório de Grupos de Pesquisa no Brasil. Censo 2004. Disponível em: <http://dgp.cnpq.br/censo2004/>. Acessos em: 15 out. 2006.

COSTA, M.C. Ainda somos poucas: exclusão e invisibilidade na ciência. Cadernos Pagu, v.27, p.455-459, 2006.
ESTÉBANEZ, M.E. As mulheres na ciência regional: diagnóstico e estratégias para a igualdade. Traduzido por: Sabine Righetti., 2003. Disponível em: <http://www.comciencia.br/reportagens/ mulheres/10.shtml >. Acesso em: 13 mar. 2006.

ESTÉBANEZ, M.E.; LÁSCARIS-COMNENO, T. La mujer y ciencia en Centroamérica: un ejercício de aplicación del enfoque del género en la construcción de indicadores. In: Taller Indicadores de ciencia y tecnología bajo un enfoque de género, 2004, El Salvador, Disponível em: <http://www.ricyt.org/interior/difusion/ pubs/elc2003/6.pdf>. Acesso em: 10 dez. 2006.

FERNÁNDEZ RIÚS, L. Roles de género: mujeres académicas, conflictos? In: CONGRESO INTERNACIONAL MULTIDISCIPLINARIO SOBRE MUJER, CIENCIA Y TECNOLOGÍA. 2., 2000, Panamá. Anais... Panamá: Universidad de Panamá, 2000. Disponível em: <http://www.oei.es/salactsi/lourdes.htm>. Acesso em: 10 dez. 2006.

FLORES ESPINOLA, A. Metodologia feminista y prática científica. In: CONGRESO IBEROAMERICANO DE CIÊNCIA, TECNOLOGIA Y GÊNERO. 6., 2006, Zaragoza. Anais... Zaragoza: Prensas Universitárias, 2006. p.213-214.

GALIZA, M. Mulheres na pesquisa: uma realidade. 2005. Disponível em: <http://www.cnpq.br/noticias/2005/080305.htm>. Acesso em: 18 maio 2005.

GONZÁleZ GARCÍA, M.I.; PÉREZ SEDEÑO, E. Ciencia, tecnologia y género. Revista Iberoamericana de Ciência, Tecnologia, Sociedad y Innovación, v.2, enero 2002. Disponível em: <http://www.oei.es/revistactsi/numero2/varios2.htm>. Acesso em: 18 maio 2005.

HARAWAY, D. Simians, cyborgs and women: The reinvention of nature. New York: Routledge, 1991.

HARDING, S. Ciencia y feminismo. Madrid: Ediciones Morata, 1996.

HAYASHI, M.C.P.I. Mulher na ciência e na tecnologia. In: SEMANA DA HISTÓRIA: A mulher na ciência, na política e na história, 2., 2003. São Carlos: UNICEP, 2003.

HAYASHI, M.C.P.I. Participação feminina na ciência e na tecnologia: um estudo sobre a representação da mulher na C\&T na UFSCar. São Carlos, UFSCar, 2005. (Projeto de pesquisa) 
HAYASHI, M.C.P.I.; HAYASHI, C.R.M.; MASTROGIROLAMO, F.D. Participação feminina na ciência e tecnologia na UFSCar. In: CONGRESSO DE INICIAÇÃO CIENTÍFICA DA UFSCAR, 12. 2004, São Carlos.

IBICT. Instituto Brasileiro de Informação em Ciência e Tecnologia. Prossiga. 2006. Disponível em: <http://prossiga.ibict.br/ fomento $>$. Acesso em: 15 out. 2006.

KELLER, E.F. Reflections on gender and science. New Heaven: Yale University Press, 1985.

KELLER, E.F. Qual foi o impacto do feminismo na ciência? Cadernos Pagu, v.7, p. 13-34, 2006.

LETA, J. As mulheres na ciência brasileira: crescimento, contrastes e um perfil de sucesso. Estudos Avançados, v. 17, n.49, p. 1-14, 2003.

LETA, L.; LEWISON, G. The contribution of women in Brazilian science: A case study in astronomy, immunology and oceanography. Scientometrics, v.57, p.339-353, 2003.

LONGINO, H. Science is social knowledge: Values and objectivity in scientific inquiry. Princeton: Princeton University Press, 1990.

LOPES, M.M. "Aventureiras" nas ciências: refletindo sobre gênero e história das ciências naturais no Brasil. Cadernos Pagu, v.10, p.345-368, 1998 .

LOPES, M.M. (Org.). Cadernos Pagu: Gênero, ciência e história. Campinas: Unicamp, n. 15, p.7-14, 2000.

LOPES, M.J.M.; LEAL, S.M.C. A feminização persistente na qualificação profissional da enfermagem brasileira. Cadernos Pagu, v.24, p. 105-125, 2005.

MACHADO, M.H. Os médicos no Brasil: um retrato da realidade. Rio de Janeiro: FIOCRUZ, 1997.

MACIEL, B. Mulheres na produção do conhecimento científico. Revista FACIPE, v. 1, n. 1, p. 15-26, 2005

MASTROGIROLAMO, F.D. Subsídios para a construção de indicadores da participação feminina na ciência e tecnologia na UFSCar. São Carlos: UFSCar, 2003. (Trabalho de Conclusão de Curso de Graduação em Biblioteconomia e Ciência da Informação)

MELO, H.P.; LASTRES, H.M.M.; MARQUES, T.C.N. Gênero no Sistema de Ciência, Tecnologia e Inovação no Brasil. Rio de Janeiro, 2004. Disponível em:<http://www.cbpf.br/ mulher/ hildete 1.pdf>. Acesso em: 15 out. 2006.

MELO, H.P.; LASTRES, H.M.M. Ciência e tecnologia numa perspectiva de gênero: o caso do CNPq. Rio de Janeiro, 2004 Disponível em: <http://www.cbpf.br/ mulher/hildete2.pdf>. Acesso em: 15 out. 2006.

MELO, H.P.; OLIVEIRA, A.B. A produção científica brasileira no feminino. Cadernos Pagu, v. 27, p.301-331, 2006.
NEAD. Núcleo de Estudos Agrários e de Desenvolvimento Rural. Encontro nacional discute a participação das mulheres nas universidades e produção acadêmica sobre gênero. 2006. Disponível em: <http://www.nead.org.br/boletim/boletim. php? boletim =327\&noticia $=1580>$. Acesso em: 10 maio 2006 .

NOGUEIRA-MARTINS, L.A. Saúde mental dos profissionais de saúde. Psychiatry on-line Brazil, v.7, n.4, 2002. Disponível em: $<$ http://www.polbr.med.br/ano02/artigo0402_a.php>. Acesso em: 20 dez. 2006.

OLINTO, G. La inserción de las mujeres en la investigación científica y tecnológica en Brasil: indicios de transformación. In: CONGRESO IBEROAMERICANO DE CIENCIA, TECNOLOGÍA Y GÉNERO. 5., 2004, Ciudad de México. Anais... Ciudad de México: 2004.

PASTORE, E.; DALLA ROSA, L. A presença da mulher nos cuidados em saúde. In: SEMINÁRIO INTERNACIONAL FAZENDO GÊNERO, 7. 2006, Florianópolis. Anais... Florianópolis: 2006. Disponível em: <www.fazendogenero7.ufsc.br/artigos/D/ Dalla_Rosa-Pastore_27.pdf>. Acesso em: 20 dez. 2006.

PÉREZ-SEDEÑ̃, E. y cols. La situación de las mujeres en el sistema educativo de ciencia y tecnología en España y su contexto internacional. Madrid: Ministerio de la Educación, Cultura y Desportes, 2004.

SCHIENBINGER, L. O feminismo mudou a ciência? Tradução de Raul Fiker. Bauru: EDUSC, 2001.

SOARES, T.A. Mulheres em ciência e tecnologia: ascensão ilimitada. Química Nova, v.24, n.2, p.281-285, 2001.

TABAK, F. O laboratório de Pandora: estudos sobre a ciência no feminino. Rio de Janeiro: Garamond, 2002.

UFSCar. Universidade Federal de São Carlos. Equipe administrativa. 2006. Disponível em: <http://www2.ufscar.br/ aufscar/equipeadmin.php>. Acesso em: 15 out. 2006.

UFSCar. SRH. Universidade Federal de São Carlos. Secretaria Geral de Recursos Humanos. Quadro de servidores. 2006. Disponível em: <http://www.srh.ufscar.br>. Acesso em: 15 out. 2006.

VELHO, L; LEÓN, E. A construção social da produção científica por mulheres. Cadernos Pagu, v. 10, p.309-344, 1998.

VELHO, L.; PROCHAZKA, M.V. No que o mundo da ciência difere dos outros mundos? 2003. Disponível em: <http://www. comciencia.br/reportagens/mulheres/09.shtml>. Acesso em: 13 março 2006.

WATSON, J.D. A dupla hélice. Lisboa: Gradiva, 1988.

YANNOULAS, S.C.; VALLEJOS, A.L.; LENARDUZZI, Z.V.A. Feminismo e academia. Revista Brasileira de Estudos Pedagógicos, v.81, n. 199, p.425-451, 2000. 
